\title{
Imagens de gênero e envelhecimento feminino na série televisiva brasileira Os Experientes
}

\section{Images of gender and female ageing in Brazilian TV series Os Experientes}

\author{
Maria Cristina Palma Mungioli \\ Programa de Pós-Graduação em Ciências da \\ Comunicação, da Escola de Comunicação \\ e Artes da Universidade de São Paulo, \\ São Paulo, SP, Brasil \\ ORCID: 0000-0002-5553-6107 \\ <crismungioli@usp.br>
}

\author{
Sílvia Dantas \\ Programa de Pós-Graduação em \\ Ciências da Comunicação, da Escola de \\ Comunicação e Artes da Universidade de \\ São Paulo, São Paulo, SP, Brasil \\ ORCID: 0000-0003-2119-9234 \\ <silviagdantas@gmail.com>
}

\author{
Rosana Mauro \\ Programa de Pós-Graduação em \\ Ciências da Comunicação, da \\ Escola de Comunicação e Artes da \\ Universidade de São Paulo, São Paulo, \\ SP, Brasil \\ ORCID: 0000-0003-1731-202X \\ $<$ mauro.rosana@gmail.com>
}

\section{Como citar este artigo (How to cite this article): \\ MUNGIOLI, Maria Cristina Palma; DANTAS, Sílvia; MAURO, Rosana. Imagens de gênero e envelhecimento feminino na série televisiva brasileira Os Experientes. Revista Famecos, Porto Alegre, v. 25, n. 3, p. 1-15, setembro, outubro, novembro e dezembro de 2018: ID29029. DOI: http://dx.doi.org/10.15448/1980-3729.2018.3.29029.}

\section{RESUMO}

O artigo analisa dois episódios da série brasileira Os Experientes (O2 Filmes; Globo, 2015) com o objetivo de observar a produção de sentido dos discursos verbovisuais sobre a mulher idosa e a velhice feminina. $\mathrm{O}$ artigo embasa-se sobre dois eixos complementares: (1) as discussões sobre o envelhecimento da população e a "feminização" da velhice (Debert, 2012; Neri, 2007; Salgado, 2002), considerando os dois fenômenos como parte integrante do profundo e complexo processo de transformação das identidades e da intimidade (Giddens, 1993, 2002) na contemporaneidade; (2) os estudos de linguagem de Bakhtin (2002, 2003), principalmente os conceitos de enunciado concreto e dialogia. A análise evidenciou a pluralidade das imagens do envelhecer feminino na contemporaneidade, destacando a presença de mulheres fortes e conscientes de suas potencialidades para além das visões tradicionais relativas ao tema.

Palavras-chave: Ficção seriada televisiva. Relações de gênero. Velhice feminina.

\section{ABSTRACT}

This paper analyzes two episodes of the Brazilian TV series Os Experientes (O2 Filmes; Globo, 2015). The objective is to observe the creation of meaning of the verbal-visual discourses about the elderly women and female aging. The article is based on two complementary axes: (1) the discussions about the aging of the population and the "feminization" of the old age (Debert, 2012; Neri, 2007; Salgado, 2002), considering both phenomena as a part of the deep and the contemporary complex transformation of the identities and intimacy (Giddens, 1993, 2002); (2) the studies of language of Bakhtin (2002, 2003), mainly concepts of concrete enunciation and dialogism. The analysis revealed the plurality of images of female ageing in the modern-day, highlighting the presence of strong women aware of their potentialities beyond the traditional approaches concerning the theme.

Keywords: TV Serial fiction. Gender relations. Elderly woman.

\section{Introdução}

O presente artigo analisa dois episódios da série Os Experientes (O2 Filmes; Globo, 2015) com o objetivo de observar a produção de sentido envolvendo a construção social da mulher idosa e da velhice feminina a partir dos discursos verbais. Embasam a discussão: (1) os estudos sobre envelhecimento da 
população e a "feminização" da velhice (Debert, 2012; Neri, 2007; Salgado, 2002) como parte integrante do profundo e complexo processo de transformação das identidades e da intimidade (Giddens, 1993, 2002) em curso na sociedade contemporânea; (2) os estudos de linguagem de Bakhtin (2003), destacando os conceitos de enunciado concreto e dialogia. Em termos específicos do estudo de séries de televisão, o trabalho considera o formato série sob a perspectiva das narrativas complexas, inserindo o tema do tratamento do gênero e de idade das protagonistas femininas no cenário atual das séries televisivas brasileiras.

\section{Velhice e "feminização" da velhice}

Nas últimas décadas, temos assistido a notáveis reconfigurações demográficas globais, e, em particular, àquelas concernentes ao aumento da população idosa. Recentemente, a Organização Mundial da Saúde (OMS) divulgou a previsão de que, até 2050, o número de pessoas com mais de 60 anos vai duplicar, situação que trará grandes mudanças sociais (Agência Brasil, 2015; Jornal do Brasil, 2015).

Esse cenário indica uma tendência mundial que também se apresenta no Brasil, onde é notório o estreitamento da base da pirâmide etária na população graças a dois fatores principais: a diminuição dos índices de fecundidade e maior longevidade acarretada por mudanças sociais e econômicas registradas nas últimas décadas no País. Segundo dados do Instituto Brasileiro de Geografia e Estatística, a quantidade de idosos subiu de 9,8\% em 2005 para 14,3\% da população brasileira em 2015, crescimento que se processou em todos os grupos etários de idosos (IBGE, 2016, p. 50). Entre tais grupos, observa-se ainda a predominância de mulheres, fenômeno que se convencionou chamar de "feminização da velhice" o qual:

coincide com mudanças nas normas etárias e de gênero que regulam os comportamentos e as expectativas de comportamento das mulheres idosas, as relações intergeracionais e os intercâmbios de apoio material, instrumental e afetivo entre gerações (Neri, 2007, p. 48).

De acordo com Neri (2007), a emergência desse fenômeno encontra-se associada a diversos fatores, como maior longevidade feminina; maior presença relativa de mulheres nos estratos mais velhos da população; o aumento do número de idosas como parte da parcela populacional economicamente ativa; e o aumento da quantidade de idosas como chefes de família. Também Salgado $(2002$, p. 9) destaca esse fenômeno demográfico afirmando que "o fato mais significativo e simples sobre a velhice é que a população idosa é predominantemente feminina". Para ela, esse fato, em geral, acarreta uma 
situação de dupla discriminação em relação às mulheres idosas: a primeira relaciona-se à idade propriamente dita (que atinge homens e mulheres) e a segunda se relaciona diretamente ao gênero feminino.

Ambas as situações ganham corpo por meio de estereótipos e preconceitos, os quais se alimentam e se retroalimentam por meio de discursos (Bhabha, 1998) e práticas sociais. Tais discursos são mediados e construídos socialmente por enunciados concretos (Bakhtin/Volochinov, 2002) que se articulam organicamente no eixo tempo-espaço (Bakhtin, 2003), no qual o tempo e o espaço são construções sociais cujos valores e ideologias velados/ desvelados compõem o enunciado concreto que deve alicerçar a interação verbal e os estilos da enunciação (Bakhtin/Volochinov, 2002).

Em sua concepção sócio-histórica da linguagem, Bakhtin/Volochínov (2002) e Bakhtin (2003) apresentam diversos conceitos que nos possibilitam aprofundar as discussões em torno dos sentidos produzidos pelos discursos verbais. No entanto, no presente texto, o conceito bakhtiniano com o qual trabalhamos para estudar os discursos verbo-visuais que compõem os episódios em análise é o de dialogia. Trata-se de um conceito basilar e complexo de toda a teoria bakhtiniana que se funda sobre o princípio da comunicação verbal. Resumidamente, podemos entendê-lo, de acordo com Bakhtin/Volochinov (2002), a partir da concepção sócio-histórica da linguagem segundo a qual as formas da comunicação verbal são determinadas pelas relações de poder e pela estrutura sociopolítica. "A situação social mais imediata e o meio social mais amplo determinam completamente e, por assim dizer, a partir do seu próprio interior, a estrutura da enunciação" (Bakhtin/Volochinov, 2002, p. 113). Para Bakhtin, trata-se de um elemento fundador de todo e qualquer discurso, uma vez que os discursos estão socialmente situados e, por isso, reproduzem, reelaboram, interpõem e refratam outros discursos existentes. Bakhtin (2003, p. 299) afirma que cada enunciado é um elo na cadeia da comunicação discursiva e gera atitudes responsivas.

Por mais monológico que seja o enunciado (por exemplo, uma
obra científica ou filosófica), por mais concentrado que esteja
no seu objeto, não pode deixar de ser em certa medida também
uma resposta àquilo que já foi dito sobre dado objeto, sobre dada
questão, ainda que essa responsividade não tenha adquirido uma
nítida expressão externa [...] (Bakhtin, 2003, p. 298).

Nesse sentido, compreende-se a obra artística (em nosso caso, os episódios analisados) como uma obra que recebe um acabamento temático que dialogicamente incorpora os elementos sociais e psicológicos e os trata esteticamente Bakhtin (2003, p. 5). 
Dessa forma, o tratamento de temas como discriminação e preconceito em relação às pessoas idosas desvela uma atitude dialógica e responsiva dos criadores da série diante dos processos que neles se baseiam em nosso País.

A discriminação e o preconceito tornam-se ainda mais evidentes numa cultura em que o corpo pode ser considerado um "capital", como afirma Goldenberg (2015), referindo-se à valorização do corpo feminino na sociedade brasileira. Em estudo comparativo sobre o significado da experiência do envelhecimento feminino no Brasil e na Alemanha, Goldenberg (2015) destaca a predominância da busca do corpo perfeito entre as mulheres de nosso País, apontando um abismo enorme entre o poder objetivo feminino (suas conquistas na vida) e a "miséria subjetiva que aparece em seus discursos" (Goldenberg, 2015, p. 40). A ênfase exacerbada na busca do corpo perfeito, considerada por Goldenberg (2015, p. 58) como um "retrocesso no processo de emancipação feminina" faz com que o envelhecer no Brasil seja considerado como momento de perda, ao contrário do que a autora constatou na cultura alemã na qual as mulheres idosas sentem-se mais emancipadas e vivem a velhice como um momento de ganhos.

No entanto, é preciso ressaltar que a experiência do envelhecimento masculino e feminino - constrói-se por meio complexos processos históricos de construção de subjetividade e autoidentidade que marcam a cultura moderna (Giddens, 1993, 2002). Dessa forma, tal experiência é marcada concomitante e organicamente pela heterogeneidade de cada trajetória de vida e pelos contextos econômico, social e familiar onde ocorre, uma vez que:

Tratar da velhice [...] é buscar acessos privilegiados para dar conta de mudanças culturais nas formas de pensar e de gerir a experiência cotidiana, o tempo e o espaço, as idades e os gêneros, o trabalho e - lazer, analisando, de uma óptica específica, como uma sociedade projeta sua própria reprodução (Debert, 2012, p. 13).

Cientes da complexidade da questão e da necessidade de uma investigação que margeia múltiplos campos do saber, destacamos em nossa análise a observação de algumas imagens do envelhecimento e suas produções de sentido nos episódios da série Os Experientes (Globo, 2014), conforme veremos a seguir.

\section{Imagens do envelhecimento feminino na tela:} discursos e produção de sentido

Ao analisar as imagens da velhice em filmes, Debert (2005) destaca o aumento da presença de idosos como protagonistas e, sobretudo, um modo 
específico de envelhecimento positivo, muito ligado à atividade e ao modo de ser tipicamente juvenil. Segundo a autora, se por um lado, as categorias de idade contribuem para a definição de atores políticos e para a criação de mercados consumidores, por outro, denotam certo borramento entre fronteiras, considerando a busca de um estilo de vida mais associado à juventude e que diz respeito à necessidade constante de atividade. Para ela, isso também pode ser percebido nas telenovelas, que têm trazido imagens mais positivas do envelhecer seguindo uma tendência de associar aos idosos os valores e as atitudes anteriormente vinculados aos jovens:

\begin{abstract}
A expressão do abandono e da solidão nas novelas tem certamentenos velhos um elemento forte, mas eles agora são também apresentados como ativos, capazes de oferecer respostas criativas ao conjunto de mudanças sociais, reciclando identidades anteriores, desenvolvendo novas formas de sociabilidade e de lazer e redefinindo as relações com a família e os parentes (Debert, 2012, p. 218).
\end{abstract}

De fato, nos últimos tempos, diversas telenovelas têm apresentado sobretudo mulheres idosas como personagens centrais de núcleos importantes de sua trama. O protagonismo de personagens idosos e seu envelhecimento também têm emergido em séries brasileiras, destacando-se protagonistas femininas acima dos 60 anos, muitas vezes septuagenárias ou octogenárias ${ }^{1}$. Com trajetórias de vida nas quais se destacam sua emancipação sexual e econômica diferentemente do tradicionalmente mostrado - e recorrente - até algum tempo atrás, essas personagens contribuem para a produção de sentidos mais heterogêneos do envelhecimento feminino e para o questionamento de alguns estereótipos relacionados à imagem dos idosos e das idosas.

Especificamente em Os Experientes, nosso objeto empírico, percebemos um maior cuidado no tratamento do tema da velhice. Ao fugir da dicotomia que geralmente marca os personagens idosos nas tramas ficcionais de televisão - embasada ora no humor ora na sisudez e conservadorismo do caráter -, a série procura desconstruir estereótipos e busca um tratamento mais complexo do processo de envelhecimento e de sua produção de sentidos na sociedade brasileira. A série apresentou o protagonismo de idosos em situações extremas ou cotidianas, procurando evidenciar nuanças humanas que desvelam estereótipos/preconceitos e propiciam ao telespectador um olhar diferenciado consoante às transformações sociais por que passa a velhice na atualidade.

1 Destacamos, a título ilustrativo, as seguintes produções nacionais que apresentaram protagonistas idosas e/ou com núcleos dramáticos com predominância de idosos em papeis que não correspondiam ao estereótipo da vida na velhice: Cinquentinha (Globo, 2009), Lara com Z (Globo, 2011), Passione (Globo, 2010-2011), Doce de Mãe (Globo, 2012), Babilônia (Globo, 2015), A Regra do Jogo (Globo, 2015-2016). 
Dos quatro episódios da série, os dois analisados neste artigo (episódio 1: O Assalto) e (episódio 4: Folhas de Outono) possuem protagonistas femininas que enfrentam situações que colocam em xeque tanto as autorrepresentações quanto os papéis sociais normalmente atribuídos a senhoras idosas.

Os Experientes pode ser classificada como uma série de antologia já que apresenta tramas e personagens distintas a cada episódio. Apesar dessa independência estrutural, há como elemento comum o tema que une os quatro episódios: o envelhecimento visto seja pelos próprios protagonistas idosos seja pelas pessoas que com eles se relacionam. Ainda estruturalmente, devemos mencionar que há personagens e lugares da cidade de São Paulo que aparecem em mais de um episódio, reforçando o caráter serial da trama. No entanto, essa inter-relação ocorre de maneira lateral conectando eventos e personagens sem interferência maior no enredo dos episódios. Essa tênue relação entre personagens e tramas funciona mais como um elemento de associação dentro do universo narrativo criado do que como elemento de inter-relação diegética propriamente dito. Entendemos que tais elementos servem para construir uma ambiência urbana e social, na qual as personagens e suas tramas se tornam verossímeis e adentram a atualidade por meio da produção de sentido da idade e do envelhecimento das personagens - de diversas classes sociais e profissões - situadas na grande metrópole econômica do país. Ao mesmo tempo, esse entrelaçamento das tramas e personagens acaba por tipificá-los e inseri-los a partir de uma visada histórico-social que pode ser observada nos discursos e na sua produção de sentidos de gênero e de idade.

Com base nos conceitos explicitados, a metodologia para análise da série consistiu na identificação de três cenas-chave nos dois episódios mencionados.

\section{$\mathrm{O}$ assalto}

O episódio passa-se em uma agência bancária no centro da capital paulista e tem como protagonistas uma mulher idosa - a médica Yolanda (Beatriz Segal) -, cliente do banco, e um jovem e inexperiente assaltante Kleber (João Côrtes). Como o próprio título indica, a trama gira em torno de um assalto a uma agência bancária executado por três jovens. Kleber é um técnico de ar condicionado recrutado para introduzir no duto de ar o armamento necessário para o assalto. No dia do assalto, surpreendidos pela ausência de um comparsa, os dois bandidos mais experientes o obrigam a participar - de arma em punho - mais diretamente do assalto. Inexperiente e desesperado, Kleber faz reféns e a situação só não se torna mais traumática devido à intervenção de Yolanda, cliente do banco, médica, que cuida do ferimento dele ao longo do episódio. Os dois acabam se aproximando e trocando confidências. Por trás da 
aparência séria e serena da cliente, há uma ex-guerrilheira que, na juventude, passou oito anos encarcerada devido à participação em um assalto a um banco durante o período da ditadura militar no Brasil. As trajetórias dos dois jovens desesperados (ela em 1972, ele na atualidade) entrecruzam-se: por motivos diferentes e tempos diferentes, ambos recorrem a expedientes extremos para atingir seus objetivos: ela pela luta política armada; ele pela luta por condições de vida melhores a fim de reconquistar a namorada.

Durante toda a narrativa, marcada pela expectativa de um desenrolar violento (sugerido até mesmo pelo nome do episódio), a chave do humor é utilizada de forma sutil, principalmente quando Yolanda usa a ironia diante de estereótipos associados à velhice. Em uma das primeiras cenas, quando utiliza o caixa-eletrônico dentro do banco, Yolanda é auxiliada pela jovem atendente da agência bancária que age guiada pelo estereótipo do idoso incapaz de lidar ou entender a tecnologia.

\footnotetext{
Yolanda (dirigindo-se à atendente do banco e olhando para a tela do caixa): Olha lá, aperte o botão... (ela aperta o botão lateral à tela). Não acontece nada!

Atendente: É que a gente precisa apertar o botãozinho aqui da tela.

Yolanda: Se é na tela, não é botãozinho, minha filha. É ícone.

Atendente: Isso. Muito bem. Aperta o iconezinho.

Momentos depois:

Yolanda: Aqui, não vai...

Atendente: É que para o botão de confirma, a gente não aperta na tela. A gente aperta o botãozinho da lateral.

Yolanda: Na lateralzinha direitinha ou na lateralzinha esquerdinha?

Atendente: Oi?
}

Cabe lembrar, conforme destacamos anteriormente, que para Bakhtin/ Volochínov (2002) a enunciação é de natureza social, já que todo enunciado se constrói direcionado e condicionado por duas forças que agem sobre o indivíduo, a individual e a social. Não se trata de forças isoladas, ao contrário, ambas se constituem semioticamente em uma relação orgânica e interdependente.

No trecho acima, dá-se o confronto de duas vozes sociais: a jovem funcionária do banco tenta parecer simpática, como percebemos pela sua voz e o tom empregado na interação com a senhora idosa. Porém, sua enunciação é marcada pelo uso frequente de diminutivos, denotando uma atitude de infantilização com relação a Yolanda. Contrariando a expectativa, Yolanda dá mostras de que o problema não é tecnologia. Durante sua conversa com a atendente, Yolanda usa a linguagem com maior domínio que a própria 
atendente ao questionar o uso inadequado que a jovem faz das palavras ao explicar como usar o equipamento. A ironia da senhora atinge inclusive a própria incoerência dos comandos das operações indicadas na tela, já que há uma enorme confusão entre o uso das palavras botão e ícone, como ela aponta. O uso de diminutivos é ironizado pela cliente, que se percebe diminuída por meio de um discurso que remete à infantilização de suas atitudes e ao descrédito de sua competência cognitiva. Dessa forma, entende-se a ironia de Yolanda, do ponto de vista dialógico, como uma atitude responsiva de sua parte a todo o conjunto de preconceitos e estereótipos cristalizados nos discursos e nas atitudes da atendente. A jovem age aparentemente de forma automática sem pensar ou escutar realmente o que Yolanda diz. Parece-nos que, dominada pelo estereótipo, a jovem trabalha com "os tipos aceitos, os padrões correntes, as versões padronizadas [que], interceptam a informação no trajeto rumo à consciência" (Lippman, 1980, p. 153).

Outro estereótipo recorrente em nossa sociedade é a associação do envelhecer a um período de perda e degradação física (cegueira, senilidade, etc.), ainda mais enfatizada quando se considera o contexto social brasileiro de valorização exacerbada da juventude e do corpo jovem (Goldenberg, 2015). A todo instante, Yolanda é qualificada como velha ou "véia" com desdém. No início da trama, o assaltante Kleber a chama de "velha zoada do cacete", ao que ela responde: "sou velha, mas não sou surda. Nem zoada."Também os policiais que cercam a agência bancária para resolver a situação referem-se à idosa por meio de termos pejorativos e desdenham inclusive a necessidade de salvaguardar sua vida:

Policial 1: Será que ela não encontrou o bilhete?

Policial 2: Vai ver que não enxergou as letrinhas, é Matusalém.

Policial 1: Depender de velho é foda.

Em outro momento, quando a polícia decide invadir o banco:

Policial 1: Eu sei ... não tem opção ...

Policial 2: Ou a gente invade, ou a gente se arrisca a ele sair matando todo mundo. Se a gente agir rápido o máximo que ele vai matar é a velha. Mas vamos combinar: já viveu a vida dela.

Em diversas cenas, o discurso verbo-visual trabalha em uma chave que subverte o esperado e expõe a fragilidade dos estereótipos e preconceitos relacionados aos idosos e à velhice. Na situação de crise, que se instaura a partir do início do assalto e da tomada de reféns pelos assaltantes, era de se esperar 
de uma senhora, exposta a essa situação de violência e medo, a submissão total às ordens e desejos do assaltante. No entanto, a juventude e a instabilidade psicológica do "bandido" não constituem ameaça para Yolanda, que ridiculariza a falta de habilidade dele com a arma e seu declarado pertencimento a uma facção criminosa: "De que departamento? Do Marketing ou do RH? Com arma é que você não sabe lidar." A fala de Yolanda, ao mesmo tempo que demonstra seu sangue frio, desnuda a fragilidade do jovem criminoso, pois se espera de um "bandido" que ele seja malvado, desumano, violento. Kleber não corresponde a essa expectativa e confessa que agiu motivado pelo dinheiro que ia ganhar para levar a namorada a uma viagem de cruzeiro marítimo, desejo que é ridicularizado pela refém: "Você é um idiota, um banana" [...]. "E cruzeiro?! Que coisa mais chata". Muitas vezes considerado como uma viagem mais direcionada ao público idoso, o cruzeiro é criticado justamente por Yolanda, cujo drama é revelado quando Kleber, em resposta às tentativas dela de fazê-lo se sentir inferiorizado e se entregar, a provoca:

\footnotetext{
Kleber: Você não sabe de nada, perua. Você não sabe nada da vida. Você não sabe o que é puxar cadeia no Brasil.

Yolanda: Ah, não, é? Eu vou te contar o que é ficar presa, meu filho. Eu fiquei 8 anos presa. E dois eu passei numa solitária.

Kleber: Você?!!!
}

O espanto de Kleber é o mesmo do telespectador, que não imagina o passado rebelde da senhora que situa em uma faixa etária cuja imagem em geral é associada socialmente à sabedoria e à calma. Ela revela então ter organizado e participado, junto como o marido, de um grande assalto em 1972.

Como vimos, a situação extrema faz emergir conflitos que refletem e refratam preconceitos e estereótipos em relação à mulher idosa que são ressemantizados por meio do tratamento temático e discursivo que enfatiza o protagonismo feminino em termos de competência para lidar com a tensão da situação do assalto.

\section{Folhas de Outono}

Em Folhas de Outono, a construção da trama ocorre em torno dos novos rumos que Francisca (Selma Egrei) imprime à sua vida após a morte do marido. Nessa nova fase de sua vida, ganham centralidade os conflitos com a família e a própria (re)descoberta da sexualidade a partir da chave da homoafetividade. O episódio tem início com Francisca, junto de seus dois filhos (um casal), no enterro do marido, Arlindo, com quem foi casada por 45 anos. Na primeira cena, 
já é possível prever que o conflito entre Francisca e seu filho Daniel (Eucir de Souza) será marcante ao longo da trama. O humor irônico da protagonista e a liberdade assumida nos primeiros tempos após a viuvez contrapõem-se aos valores tradicionais do filho, que deseja impor à mãe uma determinada forma de viver após a morte do pai. A filha Neide (Sílvia Lourenço), mais compreensiva com relação aos novos hábitos da mãe, também mostra pouca independência frente às pressões e à autoridade do irmão.

Já no início do episódio, na volta do cemitério para a casa, de carona com uma amiga, Francisca revela a vontade de comprar camisolas, vestimenta que Arlindo a proibira de usar. Em seu discurso, Francisca explicita ao mesmo tempo sua revolta e sua submissão em relação a essa determinação dele: "Uma coisa tão besta. O Arlindo não me deixava dormir de camisola. Dizia que era coisa de mulher vulgar." Seu discurso reverbera não apenas submissão e talvez arrependimento, mas demonstra também o estereótipo e o preconceito de gênero, segundo os quais à mulher casada não é possível a realização amorosa e sexual. Sexualidade, aliás, que devia ser escondida sob um pijama que, por sua vez, caracteriza-se como peça de vestuário que é usada por homens e mulheres; podendo, portanto, ser entendida como assexuada.

Em outro momento, ao conversar com a amiga Maria Helena (Joana Fomm), ela resume a vida amorosa e sexual que levava com o marido: os quinze primeiros anos de casamento como babá e motorista das crianças, os cinco últimos anos como enfermeira do marido doente e os 25 anos restantes que ela não lembra como foram passados: "onde é que eu estava nesses 25 anos, que eu não sei...." A conversa franca entre as amigas demonstra o peso da imposição social sobre as mulheres e seu próprio corpo:

Maria Helena: Vem cá, quanto tempo você não sentia o seu corpo dando sinais de vida? Francisca: Não sei, Maria Helena, eu não fui educada pra sentir essas coisas.

Maria Helena: Nós não fomos.

Como analisa Giddens (1993), durante muitas décadas o confinamento da sexualidade feminina ao casamento era considerado símbolo da "respeitabilidade" da mulher. O papel social feminino era restrito ao lar e ao cuidado com filhos e marido, de forma que a situação do casamento permanecia como a meta principal na vida das mulheres, cujas vidas gravitavam em torno das tarefas domésticas e da construção do ideal da boa esposa e rainha do lar. Por essa razão, diante das pressões sociais, muitas idosas identificam a liberdade como grande conquista dessa etapa, uma vez que não há necessidade da dedicação da vida aos filhos, maridos (Debert, 2012). 
A morte do marido e a descoberta de que fora traída durante o casamento impulsionam a personagem a viver a liberdade que nunca tivera e, posteriormente, a relacionar-se amorosamente com Maria Helena, sua vizinha, que também está sozinha após a morte da mãe. Porém, o filho ainda representa em sua vida a voz da tradição ultrapassada, do machismo, que deseja dela um comportamento de acordo com os valores tradicionais. $\mathrm{O}$ discurso retrógrado do filho é questionado pela ironia de Francisca, como apresenta o seguinte trecho, no qual os filhos almoçam na casa da mãe.

Daniel (referindo-se à decoração da casa): Já fez muitas mudanças, né?

Francisca: Algumas, né? Eu entendi muito bem o tom do "já". Já se passaram mais de três meses.

Daniel: Mas não tem mais a presença do papai.

Francisca: Podia fazer uma sessão espírita e invocar a presença dele.

Neide: Não começa mãe. Eu achei que ficou tudo lindo.

Daniel: Não sei se ele gostaria.

Francisca: Ainda bem que ele tá morto, né?, assim ele não fica chateado. [...]

Daniel: O problema é o mesmo de sempre. Eu acho que ainda não chegou a hora de tirar o luto.

Neide: Daniel, dá para você parar de ser idiota, por favor? A mamãe tá feliz, fica feliz você também. Isso é uma coisa boa.

Daniel: Eu não vejo nada de bom da gente simplesmente esquecer o papai. [...] Vocês não entendem a dor dos homens.

Neide: Que dor, Dani, aquela que você sente quando te dão um chute no saco?

Daniel: Quase, porque você ver a sua mãe bancando a viúva alegre e falando merda é um chute no saco.

Francisca: É melhor você ficar quieto.

Daniel: Ficar quieto pra quê? O que você vai fazer? Agora você vai anunciar que arranjou um namoradinho? Só falta isso.

Em seguida, Francisca chama Maria Helena e a apresenta como sua namorada para os filhos. Na voz de Daniel surge o discurso que justifica a opressão à mulher como forma de manutenção dos valores tradicionais e da supremacia patriarcal. No final do episódio, depois de um ano da morte do pai, Neide convida a mãe e a namorada para um almoço, a pedido do irmão. Ao chegar, Francisca percebe que Daniel também convidou os amigos da família. 0 intuito do rapaz era fazer a mãe entrar em contato novamente com as pessoas de seu passado e desistir do romance com Maria Helena. 
Durante a reunião, Francisca descobre que o filho sempre soubera que Arlindo a traía com uma amiga de ambos, também presente no almoço. Cansada de mentiras, Francisca resolve dar um basta à hipocrisia reinante. Após discutir com a amante do marido, ela revela a todos seu romance com Maria Helena e deixa a festa com a namorada.

O relacionamento homoafetivo de Francisca e Maria Helena traz para a TV aberta a questão da sexualidade como aspecto maleável do eu, tema desenvolvido por Giddens (1993), para quem:

Hoje em dia a"sexualidade"tem sido descoberta, revelada e propícia ao desenvolvimento de estilos de vida bastante variados. É algo que cada um de nós "tem", ou cultiva, não mais uma condição natural que um indivíduo aceita como um estado de coisas preestabelecido. De algum modo, que tem de ser investigado, a sexualidade funciona como um aspecto maleável do eu, um ponto de conexão primário entre o corpo, a autoidentidade e as normas sociais (Giddens, 1993, p. 25).

De acordo com a ideia de que a identidade é construída e reconstruída com as experiências do sujeito, a sexualidade também pode ser entendida como um ponto de encontro entre o desejo e a autoidentidade. Ao que parece, Francisca passa a ser mais independente das coerções sociais (e familiares), inclinando-se ao seu novo momento de autodescoberta e liberdade. Com isso, as tradições familiares são confrontadas a partir de dois eixos no episódio: (I) a libertação feminina associada à (II) sexualidade na velhice feminina (inclusive por meio de um relacionamento homoafetivo) contribuindo para uma concepção mais maleável de família.

É importante pontuar que a liberdade também é trabalhada no episódio por meio da aceitação da velhice, encarada de forma transparente. Francisca e Maria Helena, inclusive, tratam a questão com humor. "Velha, quando fecha o olho, dorme", zomba Francisca quando a namorada Ihe pede que feche os olhos para uma surpresa. Ela se apropria, nesse caso, das piadas existentes na sociedade sobre a velhice. Porém, tal enunciado ganha novos sentidos já que para ela a velhice representa novas oportunidades de vida. Dessa forma, ao longo do episódio, a linguagem verbal erige-se sob o princípio da responsividade e é matizada pela pluralidade de vozes que a compõem tanto em termos de futuro quanto em termos de passado, constituindo o princípio dialógico que segundo Bakhtin (2003) rege as interações e a comunicação verbal.

\section{Conclusões}

Observamos por meio da análise realizada que a abordagem temática da velhice ganha matizes diferentes nos dois episódios analisados, na medida 
em que apresentam formas distintas de viver a velhice: enquanto Yolanda $(O$ Assalto) vive como se sua vida não mais tivesse sentido após a morte do marido (companheiro) há mais de quarenta anos, a personagem Francisca (Folhas de Outono) renasce a partir das mudanças decorrentes da morte do marido, trazendo um período de novas descobertas.

Em ambos os episódios, observa-se a presença de mulheres fortes que se agigantam diante de adversidades e que buscam seu lugar social para além dos modelos que tentam enquadrá-las sob o peso de estereótipos que se somam: (1) incapacidade de autonomia por serem mulheres e (2) incapacidade de autonomia por serem idosas. Diante dessa situação duplamente opressora, elas respondem com a altivez de mulheres que não abandonam a luta e se firmam como indivíduos plenos e cientes de sua relevância social.

\section{Referências}

AGÊNCIA BRASIL EBC. OMS estima que número de pessoas com mais de $\mathbf{6 0}$ anos dobre até 2050, 30 set. 2015. Disponível em: <http://agenciabrasil.ebc.com.br/ internacional/noticia/2015-09/oms-alerta-que-numero-de-pessoas-com-maisde-60-vai-dobrar-ate-2050>. Acesso em: 24 out. 2015.

BAKHTIN, Mikhail. Estética da Criação Verbal. Tradução: Paulo Bezerra. São Paulo: Martins Fontes, 2003.

BAKHTIN, Mikhail (V. N. Volochinov). Marxismo e Filosofia da Linguagem. São Paulo: Hucitec Annablume, 2002.

BHABHA, Homi K. O local da cultura. Belo Horizonte: Ed. UFMG, 1998.

DEBERT, Guita Grin. A vida adulta e a velhice no cinema. In: GUSMÃO, Neusa Maria Mendes de (org.). Cinedebate: cinema, velhice e cultura. Campinas, SP: Alínea, 2005, p. 23-44.

DEBERT, Guita Grin. A reinvenção da velhice. São Paulo: Editora da Universidade de São Paulo: Fapesp, 2012.

GIDDENS, Anthony. A transformação da intimidade: sexualidade, amor e erotismo nas sociedades modernas. São Paulo: Editora da Universidade Estadual Paulista, 1993.

GIDDENS, Anthony. Modernidade e identidade. Rio de Janeiro: Jorge Zahar, 2002.

GOLDENBERG, Mirian. Coroas: corpo, sexualidade e envelhecimento na cultura brasileira. Rio de Janeiro: BestBolso, 2015.

INSTITUTO BRASILEIRO DE GEOGRAFIA E ESTATÍSTICA. Síntese de indicadores sociais: 
uma análise das condições de vida da população brasileira. Rio de Janeiro: IBGE, 2016. Disponível em: <http://biblioteca.ibge.gov.br/visualizacao/livros/ liv98965.pdf>. Acesso em: 05 mar. 2017.

JORNAL DO BRASIL. OMS: Número de pessoas com mais de 60 anos de idade deverá duplicar até 2050. 30 set. 2015. Disponível em: <http://www.jb.com.br/cienciae-tecnologia/noticias/2015/09/30/oms-numero-de-pessoas-com-mais-de-60anos-de-idade-devera-duplicar-ate-2050/>. Acesso em: 24 out. 2015.

LIPPMANN, Walter. Estereótipos. In: STEINBERG, C. S. (org.). Meios de comunicação de massa. São Paulo: Cultrix, 1980.

NERI, Anita Liberalesso. Feminização da velhice. In: NERI, Anita Liberalesso (org.). Idosos no Brasil: vivências, desafios e expectativas na terceira idade. São Paulo: Fundação Perseu Abramo, Edições SESC SP, 2007, p. 47-64.

OS EXPERIENTES. Direção: Fernando Meirelles, Quico Meirelles e Gisele Barroco. Produção: Fernando Meirelles, Andrea Barata Ribeiro e Bel Berlinck. Autores: Marcio Alemão Delgado e Antônio Prata. Brasil: Globo, 2015. 4 episódios, 40 min. cada. Disponível em: < https://globoplay.globo.com/os-experientes/p/8680/>. Acesso em: 02 nov. 2017.

SALGADO, Carmen Delia Sánchez. Mulher idosa: a feminização da velhice. Estudos Interdisciplinares sobre o Envelhecimento, Porto Alegre, v. 4, p. 7-19, 2002. Disponível em: <http://www.seer.ufrgs.br/RevEnvelhecer/article/view/4716>. Acesso em: 10 set. 2013. 
Recebido em: 03/11/2017

Aceito em: 12/03/2018

Dados das autoras:

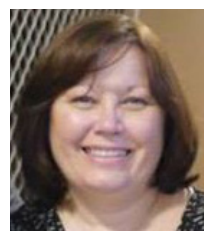

Maria Cristina Palma Mungioli | crismungioli@usp.br

Escola de Comunicações e Artes da Universidade de São Paulo - ECA-USP

Professora doutora do Depto. de Ciências da Comunicação da Escola de Comunicações e Artes da

Universidade de São Paulo - ECA-USP Professora do Programa de Pós-graduação em Ciências da

Comunicação - PPGCOM-USP. Lider do Grupo de Pesquisa GELIDIS ECA-USP/CNPq.

\author{
Endereço da autora: \\ Programa de Pós-Graduação em Ciências da Comunicação \\ Escola de Comunicação e Artes da Universidade de São Paulo \\ Av. Prof. Lúcio Martins Rodrigues, 443 \\ 05508-020 - São Paulo (SP) - Brasil
}

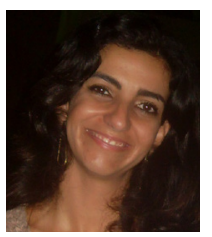

Sílvia Góis Dantas | silviagdantas@gmail.com

Escola de Comunicações e Artes da Universidade de São Paulo - ECA-USP

Doutoranda no PPG-COM da Universidade de São Paulo.

Integrante do Grupo de Pesquisa GELIDIS ECA-USP/CNPq.

Endereço da autora:

Programa de Pós-Graduação em Ciências da Comunicação

Escola de Comunicação e Artes da Universidade de São Paulo

Av. Prof. Lúcio Martins Rodrigues, 443

05508-020 - São Paulo (SP) - Brasil

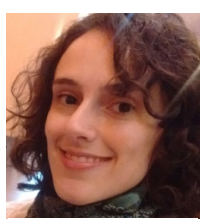

Rosana Mauro | mauro.rosana@gmail.com

Doutoranda no PPG-COM da Universidade de São Paulo.

Integrante do Grupo de Pesquisa GELIDIS ECA-USP/CNPq.

Endereço da autora:

Programa de Pós-Graduação em Ciências da Comunicação

Escola de Comunicação e Artes da Universidade de São Paulo

Av. Prof. Lúcio Martins Rodrigues, 443

05508-020 - São Paulo (SP) - Brasil

Nota explicativa: $O$ artigo Imagens de gênero e envelhecimento feminino na série televisiva brasileira Os Experientes submetido à Revista FAMECOS foi escrito pelas três autoras que o assinam. Trata-se da aplicação de uma metodologia de análise a ser utilizada pelas duas orientandas da autora principal em suas pesquisas de doutorado no PPGCom-ECA/USP. O recorte temático comum às duas teses refere-se ao estudo da construção verbo-visual do gênero feminino em ficções televisivas seriadas. $O$ artigo foi escrito a seis mãos e utiliza parte do referencial teórico e alguns dos procedimentos de análise que serão empregados nas teses e que compõem o quadro das pesquisas realizadas pela orientadora.

Contribuições das autoras: As três autoras fizeram contribuições substanciais para concepção, desenvolvimento, redação e revisão crítica do trabalho. O episódio "O assalto" coube à doutoranda Rosana Mauro e o episódio "Folhas de Outono" à então doutoranda Silvia Dantas. O delineamento da proposta do artigo, o embasamento da discussão teórica, a orientação dos procedimentos de análise, a interpretação dos resultados, bem como a redação final do artigo couberam à autora principal, Profa. Maria Cristina Palma Mungioli (PPGCom-ECA/USP). Todas aprovaram a versão final para publicação. 